\title{
Modern biotechnology: search for an optimal model of legal regulation
}

\author{
Denis Matytsin, Olesya Kazachenok, and Agnessa Inshakova* \\ Volgograd State University, Volgograd, Russia
}

\begin{abstract}
This chapter justifies the conclusion that GMO technologies as a form of biotechnology are the greatest technological breakthrough of our time. With the help of GMOs, it is possible to increase the yield, which allows not only to solve the problems of world food security, but also to preserve untouched lands from human impact (including through the creation of national parks or other types and forms of specially protected natural areas there). The use of GMO technologies reduces the use of pesticides and agrochemicals in agriculture. However, in conditions where the harm from GMO technologies and products not convincingly proven, the search for an optimal model for their use should continue. The authors note that the concept of sustainable development implies a balance of environmental, economic and social interests. Deviation from this balance in any direction entails a number of negative consequences for the entire society, both in terms of problems with the realization of the right to food, as well as in terms of environmental protection. In this situation, it seems appropriate not to ban GMOs absolutely (as in Russia), which means the uselessness of the law of the relevant state as a regulator of public relations. Considering the measures of state regulation of the use of GMO technologies and products, the authors focus on the prospects for the use of certification and labeling of GMO products, which in a number of BRICS and EAEU countries has already had a positive effect.
\end{abstract}

\section{Introduction}

Other studies of the potential dangers of GMOs are more objective, while the discussion between supporters and opponents of GMOs, who differently assess the degree of safety of products produced with their help, has no end. Despite the high public demand, there is still no accurate information about the presence of danger (or its absence) in the use of agricultural GMO products. It has not yet been possible to prove harm to human health from GMO technologies, although some types of products produced in violation of technologies have caused such harm, which has already proven several times in the courts of a number of countries.

In addition to possible harm to health, a separate problem of handling GMOs is the presence of potential or real harm to the environment. The fact is that GMO technologies

\footnotetext{
* Corresponding author: ainshakova@list.ru
} 
can not only improve the resistance to climate factors or weeds of cultivated agricultural plants, but also lead to increased survival of the weeds themselves.

Taking in to account above circumstances it is necessary to study the problem of the use of GMO technologies in agriculture from the standpoint of legal science. Of course, such a study will not be able to give recommendations on the use of a certain type of GMO products (this question is rather from the field of biological or medical science). However, it is through legal means that the use of GMO technologies in individual countries or their regions can recommended or prohibited, and a list of measures is defined to assess the quality of the product and give the results of such an expert assessment legal significance. Finally, it is the legal means, that allow us to guarantee the information rights of consumers, to regulate the procedural features of the consideration of cases for compensation for harm caused by the use of GM products.

\section{Materials and methods}

In the course of the research, general scientific methods used, including formal-logical, dialectical, system-structural, and critical cognition. Methods of synthesis, classification, and generalization used to interpret the results of the study. Private scientific methods also used in the work: formal-legal, the principle of assessing legal processes, the method of comparative analysis, etc.

\section{Results and discussion}

Today, more than 100 lines of transgenic plants grown on a production scale in the world, the undisputed leader among which is soy, which accounts for $98 \%$ of the total number of genetically modified plants. Two-thirds of all genetically modified crops in the world are cultivated in the United States. The primary objectives of creating genetic modifications were to obtain high yields, achieve resistance to drought and cold, and a number of others. Now we are talking about the creation of vitamin-rich organisms, with a regulated fat content. The use of GMOs in the production of agricultural products and food products is of great importance in terms of food security. Despite this, the prevailing opinion about the use of GMOs is that there is a potential threat to human health and the gene pool of the nation as a whole, and there is no single definition of GMOs in legal science.

According to some authors, a genetically modified organism is an organism whose genetic material has been modified using genetic engineering methods [1]. Others believe that a genetically modified organism used to grow agricultural products of plant origin is a plant organism (its parts, including seeds). In which the genetic material has received such changes that cannot obtained in natural conditions in the process of natural recombination, and which is used to increase crop yields, change the quality indicators of agricultural products [2]. Agreeing with the latter definition it noted that GMO technologies should considered in a broader context - as a kind of biotechnology that has long used by humanity.

The term "biotechnology" first proposed in 1917 by the Hungarian engineer K. Jereki [3]. Trying to eliminate the gaps in national law, in the second half of the XX century, A. Sasson (1987) [4] defined biotechnology as a technological process implemented using biological systems - living organisms and components of a living cell. At moment, there is no unified scientific opinion in the understanding of biotechnologies. They interpreted as a set of methods and techniques for obtaining useful products and phenomena for humans using biological agents [5]. As a special social activity aimed at the practical transformation of the surrounding world and oneself by a person through use of biological processes and 
agents [6]. As a science of ways to obtain target products using biosynthesis controlled by environmental parameters or genetic-engineering manipulations or a combination of these effects [7]. The latter position seems to us the most successful.

So biotechnology is a field of applied biology, which involves the use of living organisms and biological processes in engineering, technology, medicine and other areas in which biological products needed. In the legal sense, "biotechnology" means any type of technology related to the use of biological systems, living organisms or their derivatives for the manufacture or modification of products (processes) for the purpose of their direct use. The Russian Federation has joined the Convention on Biological Diversity in 1992, but it has not signed the Protocol on Biosafety (the Cartagena Protocol) to this convention.

Summarizing all of the above, we note that a GMO is an organism or several organisms, any non-cellular, unicellular or multicellular formation capable of reproducing or transmitting hereditary genetic material, other than natural organisms, obtained using genetic engineering methods and containing genetically engineered material, including genes, their fragments or combinations of genes. Modification of the genome of an organism is one of the methods of biotechnology (although not the only one), and modern agricultural biotechnologies are almost identical to the use of genetic engineering and the use of GMOs. Taking into account the polarity of opinions on the usefulness / danger of GMO technologies and products for human health and the environment, we will try to systematize the positions of different sides of this discussion.

In turn, opponents of GMOs report the first death of a person who ate food obtained using GMO technologies in a Spanish hospital in 2015. Medical examiners then determined the cause of death as result of consumption of tomatoes containing fish-related genes and antibiotic-resistant genes that prevented the development of white blood cells. There are also examples showing that concerns about the safety of GM foods have been justified in relation to potential exposure and risk in a number of other countries. For example, a study conducted by the Department of Food Science and Technology at the University of Nebraska found that a gene produced from Brazil nuts when introduced into GM soy causes allergies in humans [8].

The danger of GMO technologies is much more reasonable from the point of view of its impact on the environment. Opponents of GMOs are undoubtedly right in their concerns in the sense that ignoring the laws of evolution and population genetics and invading the genetic program of an organism is very dangerous, especially when it caused by the shortterm financial benefits of individuals, companies or financial groups [9]. Such risks are associated with the emergence of super weeds, the formation of new, poison-resistant insect populations, genetic contamination, and the permanent loss of traditional crop varieties [10].

On the other hand, all officially registered cases of harm to the health of citizens or nature occurred not because of the use of the achievements of genetic engineering as such, but because of the fact that specific companies-producers of agricultural GMO products incorrectly applied the appropriate technology. Accordingly, genetic engineering is a manifestation of scientific and technological progress, which cannot prohibited [11]. Therefore, in our opinion, further discussions on the applicability of GMO technologies in agriculture conducted not from the standpoint of a complete ban or permission of GMOs, but in the direction of finding a balance of private and public interests, a compromise between the authorities, the public and agricultural producers. At the same time, it is necessary to look for new criteria of objectivity when evaluating the results of the use of genetic engineering methods, since this innovative industry has not yet received its development and acceptance by all countries of the world.

It seems that over time the results of the use of GMO technologies in agriculture in those countries where they allowed, will allow us to conduct convincing studies that can 
make an unambiguous conclusion about the danger or harmlessness of GMO products. At moment, the task of legal science is to offer an intermediate compromise, with the guarantee of the rights and legitimate interests of citizens (the development of labeling, expertise, judicial guarantees, etc.).

From the point of view of international law, there are two main approaches to the permissibility of the use of GMOs in agriculture:

1) the principle of equivalence of products obtained using GMO technologies and "natural" products. This principle assumes the safety of GMO-containing products, which confirmed by the regulatory requirements for the quality and safety of food products.

This approach used in Canada, the United States, and some other countries. Accordingly, the main object of control is not the manufacturing process, but the product itself, which is subject to appropriate labeling.

2) the precautionary principle of handling GMO products. This principle is a significant restriction (or complete ban) on the use and import of GM organisms in a particular country. It based on the thesis that at moment the world science is not sufficiently aware of the results of the impact of GMOs on the environment and human health. In particular, this principle implemented in the Russian Federation.

The latter principle closely related to one of the basic principles of environmental law, provided for by both international and national law. For example in Russia and other EAEU countries, the principle of prohibiting economic and other activities whose consequences are unpredictable for the environment is established (Article 3 of the Federal Law "On Environmental Protection" of January 7, 2002). The implementation of this principle is one of the additional guarantees of protecting the right of everyone to a favorable environment. In order for this guarantee to be able to work in full force, we consider it necessary to amend the civil legislation, recognizing GMO technologies as a type of sources of increased danger with the resulting consequences.

It seems that even in countries where there is a complete ban on the use of GMO technologies in agriculture, it is necessary to develop research activities in this area. Since the appropriate scientific support for genetic engineering will allow in the future to more accurately determine the nature and extent of the impact of GMO technologies and products on the environment and human health. At the same time, the results of such studies should be open for general access - this will ensure the implementation of the constitutional principles of transparency, public participation in solving problems of environmental protection, and the formation and improvement of the level of environmental and legal culture of citizens.

It is necessary to give a positive assessment of the experience of the European Union, which provides for strict requirements for the labeling of GMO products. This expressed in the fact that the notification of the placement of GMOs on the market must contain a proposal for labeling. The imperative of this rule is extremely positive. Since the norm informs the buyer about the content of the product and is regarded as an effective trend in the legislation on the labeling of GMO products. Along with the legal regulation of the production of GMO products, EU legal acts pay much attention to such a property of GMOs as "traceability" (traceability). This means the ability to detect GMOs and products made from GMOs at all stages of their placement on the market through, the use of production and sales chains [12].

Among other measures for the legal regulation of relations in the field of the use of GMOs, it is necessary to highlight the existing bans in a number of European countries on the cultivation of genetically modified varieties of agricultural plants. Bans on lands that intended for the production of organic products and raw materials, as well as those that have granted the status of a special zone for the production of raw materials used for the production of baby food and dietary food. Therefore, it seems appropriate to adopt special 
rules for the coexistence of genetically modified varieties of agricultural plants with traditional and organic agricultural crops. In addition, the issue of a single list of GMOs that do not pose a threat to human health or the environment also needs to discuss. And also on measures of state support for genetic engineering research, scientific and practical developments in the field of biological and genetic safety in the creation and practical use of GMOs for economic purposes.

It is also necessary to fix in national legislation the obligation to create buffer zones for GMO producers when growing these agricultural products, separating the crops of GMO crops from traditional varieties of agricultural plants. At the same time, such zones established on land plots. At the expense of their area of the commodity producer, that uses GMOs in the cultivation of agricultural products of plant origin [5].

\section{Conclusion}

Currently, GMO crops cover more than 200 million hectares. This is $1.5 \%$ of the US territory or more than $10 \%$ of the world's crop. Since 1996, when GMOs began to used commercially for the first time, their plantings have grown more than 100 times. This is the fastest growing technology. The reason this is happening is because it the greatest technological breakthrough of our time. This is a revolution comparable to the smelting of the first metals or to the Neolithic revolution, with the domestication of domestic animals and plants. With the help of GMOs, it is possible to increase the yield, which allows not only to solve the problems of world food security, but also to preserve untouched lands from human impact (including through the creation of national parks or other types and forms of specially protected natural areas there).

The use of GMO technologies reduces the use of pesticides and agrochemicals in agriculture. Undoubtedly, the introduction of such a complex technology into production inevitably creates certain risks for nature and human health, the study and discussion of which continued. However, in conditions where the harm from GMO technologies and products not convincingly proven, it is necessary to find a compromise between private and public interests. As you know, the concept of sustainable development involves the search for a balance of environmental, economic and social interests. Deviation from this balance in any direction entails negative consequences for the entire society, both in terms of problems with the realization of the right to food, as well as in terms of the state of the environment. In this situation, it seems appropriate not to absolutely ban GMOs (as in Russia), which means that the law of the relevant state as a regulator of public relations is useless. It is necessary to build a complex legal compromise, for example, with the prohibition of not all GMO products, but only the part of it that intended for children or pregnant women. Otherwise, the whole society loses.

Instead of banning GMOs, it is necessary to develop and improve the legal mechanism for the production of agricultural products using GMOs. In particular, it is necessary to regulate the issues of state control and examination of product quality, its labeling, certification, licensing, and improve the mechanism of legal responsibility.

\section{Acknowledgments}

The reported study was funded by RFBR according to the research project No. 18-2916132. 


\section{References}

1. N. V. Bogatyreva, Bulletin of the Saratov State Law Academy, 2, 135 (2015)

2. O. I. Meniv, Legal support for the use of GMOs in the cultivation of agricultural products of plant origin in Ukraine and the EU (2016)

3. M. Bhardwaj, Asian Biotechnology and Development Review, 6(1), 39 (2003)

4. A. Sasson, Biotechnology: achievements and hopes (1987)

5. E. I. Karavaeva, R. V. Kravtsov, Siberian Legal Bulletin, 3, 7 (2005)

6. E. V. Vorontsova, Izvestiya Kursk State Technical University, 3, 113 (2010)

7. T. G. Volova, Biotechnology (1999)

8. S. K. Balashanmugam, BRICS Law J., 5(1), 27 (2018)

9. D. E. Matytsin, Internet-investing as a remote algorithm of the retail investment financing. Modern Global Economic System: Evolutional Development Vs. Revolutionary Leap (2021)

10. A. H. Scott, Villanova Environmental Law J., 26, 145 (2015)

11. V. V. Tarakanov, A. O. Inshakova, A. I. Goncharov, Proceedings of the International Scientific Conference in Memory of Oleg Inshakov (1952-2018) (2020)

12. O. P. Kazachenok, A. V. Lavrentyeva, Studies in Computational Intelligence, 826, 333 (2019) 